\title{
A VISITA DAS FADAS: TECENDO APRENDIZAGENS NA ESCOLA A PARTIR DAS FOTOGRAFIAS DE ANDRÉA BRÄCHER
}

\author{
THE FARIES VISIT: WEAVING LEARNINGS AT SCHOOL BASED ON PHOTOGRAPHS BY \\ ANDRÉA BRÄCHER
}

https://orcid.org/0000-0002-7689-2135 Graziela dos Santos Silva Ceceltski ${ }^{\text {A }}$

${ }^{\text {A }}$ Universidade Federal de Pelotas (UFPel), Tunas, RS, Brasil

Recebido em: 3 dez. 2021 | Aceito em: 10 jan. 2022 Correspondência: Graziela (sgrazii@gmail.com)

\begin{abstract}
Resumo
O presente trabalho tem como proposta apresentar e discutir a realização de um projeto desenvolvido com crianças entre nove e dez anos, alunos do $4^{\circ}$ ano do Ensino Fundamental da Escola Estadual de Educação Básica Laura Klaudat, localizada em Tunas/RS. Objetivouse apresentar a história da fotografia e instigar a curiosidade e a imaginação dos estudantes a partir do trabalho da fotógrafa Andréa Brächer de sua série intitulada "A vinda das fadas". Com esse trabalho, que articula realidade e ficção, foi possível discutir tais aspectos com os alunos através de uma série de atividades, sendo plausível perceber que os alunos se apropriaram do conhecimento sobre fotografia pelo seu envolvimento no projeto, bem como pela incorporação de debates sobre a fotografia em outras aulas e atividades, as quais integraram estudantes de outras séries e a comunidade escolar em geral.
\end{abstract}

Palavras-chave: Fotografia; Ensino de arte; Andréa Brächer; Imaginação.

\begin{abstract}
The present work proposes to present and discuss the realization of a project developed with children between nine and ten years old, students of the 4th year of Elementary School Laura Klaudat, located in the city of Tunas, RS. The objective was to present the history of photography and instigate the curiosity and imagination of students based on the work of the photographer Andréa Brächer and her series entitled "The coming of the fairies". Based on this work that articulates reality and fiction, these aspects were discussed with the students through a series of activities. From the activities carried out in the classroom, it was possible to see that students appropriated their knowledge about photography through their involvement in the project, as well as through the incorporation of debates about photography in other classes and activities, which included students from other grades and the school community in general.
\end{abstract}

Keywords: Photography; art education; Andrea Brächer; Imagination. 


\section{Introdução ${ }^{\mathrm{i}}$}

Sobre a fotografia, é possível dizer que em um instante a imagem diante da câmera deixa de ser presente e se torna o passado registrado em um pedaço de papel ou em um arquivo digital pois, desde que a câmera fotográfica começou a existir, realizar fotografias faz parte da nossa vida, com a diferença de que antigamente as fotos eram ampliadas, agora geralmente são armazenadas em dispositivos próprios ou em redes de servidores de internet. Diante dessa característica da vida contemporânea foi proposto um projeto voltado aos alunos do $4^{\circ}$ ano do Ensino Fundamental da Escola Estadual de Educação Básica Laura Klaudat, localizada no município de Tunas, Rio Grande do Sul. A iniciativa propõe que eles possam conhecer um pouco mais sobre a fotografia, desenvolvendo uma visão crítica sobre sua presença no cotidiano e na arte.

Para que isso fosse possível, foi desenvolvido um projeto com nove encontros que aconteceram semanalmente na disciplina de Produções Interativas, nos dias 03 de setembro a 11 de novembro de 2021, sempre nas quintas ou sextas-feiras de cada semana. Os encontros foram organizados a partir das seguintes atividades: observação de imagens em uma caminhada pelas ruas da cidade; roda de conversa; apresentação de documentário sobre a História da fotografia; apresentação e debate sobre o fotógrafo Eadweard Muybridge; a visita das fadas na sala de aula, inspirada pelo trabalho da artista Andréa Brachër com apresentação de seu trabalho; um debate estabelecendo paralelos entre os artistas apresentados, debatendo realidade e ficção na fotografia; produção de fotografias pelos alunos; realização de exposição; e por fim, uma conversa com a artista Andréa Brächer.

Todas essas atividades foram organizadas e pensadas para que as crianças pudessem conhecer um pouco sobre a história da fotografia, mais especificamente as obras de Brächer, que trabalham com o aspecto lúdico. A partir da história narrada pela fotógrafa que inspirou sua obra "A vinda das fadas", procurou-se convidá-los a refletir se tudo que vemos realmente pode ser considerado verdade, sobre qual o papel da fotografia no debate sobre realidade e ficção. Esse projeto procurou também estimular os estudantes a produzirem suas próprias fotografias usando a criatividade a partir das questões apresentadas.

Aprender sobre essa história riquíssima é com certeza necessário. Quando passamos a conhecer a história de algo tão importante começamos a olhar para ela com outros olhos, com interesse e curiosidade. É esse olhar crítico que queremos que as crianças tenham desde pequenas, que possam ser questionadoras e entenderem de onde vem as coisas que temos hoje. Muitas vezes, no contexto escolar a fotografia acaba ficando um pouco esquecida. Como afirma Elane Abreu (2013, p. 2), a fotografia tem "situado dilemas que a arte fotográfica tem atravessado para colocar-se no mundo como um campo de forças que capta aspectos da vida sensória e social".

Contudo, apesar de ser um tema importante para ser trabalhado em sala de aula, nem sempre temos recursos e a formação necessária para isso. No entanto, podemos adaptar seu ensino a nossa realidade, levando os alunos a se encantarem sobre o assunto e perceber a variedade e complexidade da fotografia, e, no caso desse projeto, através do delicado e envolvente tema das fadas. Na idade dos alunos contemplados por esse projeto o mundo da 
imaginação e do faz de contas ainda está vivo em suas vidas, é uma fase que precisa ser aproveitada intensamente, pois logo deixarão esse encanto pelo mundo da fantasia, começarão a fazer descobertas e irão amadurecer para entrar na adolescência. Nesse sentido, parece interessante trabalhar a fotografia e seus limites entre a fantasia e a realidade em sala de aula.

\section{Metodologia}

A metodologia aplicada para esta investigação teve em vista as proporções reduzidas de um projeto de curta duração trabalhado com apenas uma turma de estudantes, constituindo-se como uma pesquisa-ação. Nesse sentido, desenvolver uma investigação no ambiente escolar é muito propício, pois podemos perceber e nos inserir dentro deste contexto, observando de perto o que faz sentido para as crianças, o que as move e dá prazer. Fotografar e ser fotografado é com certeza uma prática habitual de crianças e adolescentes, sendo este processo intensificado pelo uso das mídias sociais, as quais tem feito parte de suas rotinas e tomado conta cada vez mais cedo da vida de todos os seres humanos.

Para Vieira (2011, p. 92), “a pesquisa-ação é, portanto, um tipo de pesquisa qualitativa que se pode apontar como exemplar no que se diz respeito a interação entre pesquisador e objeto". No intuito de mudar a realidade de percepção dos educandos para que possam desde pequenos questionar e não aceitar tudo como verdades absolutas. De acordo com o autor (idem, p. 88):

[...] a natureza da pesquisa qualitativa exige um olhar aprofundado do contexto e do local em que é executada e, também, uma interação entre o pesquisador e o objeto. $\mathrm{O}$ olhar frio e distanciado de um observador não seria capaz de aprender muitas das informações que podem estar disponíveis. O pesquisador estará em um processo de imersão na sua pesquisa, portanto.

Para a organização e planejamento do projeto o ponto de partida foi a pesquisa teórica bibliográfica, sobre a qual as autoras Eva Maria Lakatos e Mariana de Andrade Marconi dizem que:

Toda pesquisa deve basear em uma teoria, que serve como ponto de partida para investigação bem-sucedida de um problema. A teoria, sendo instrumento de ciência, é utilizada para conceituar os tipos de dados a serem analisados (LAKATOS; MARCONI, 2006, p. 17).

Dessa forma, para o presente estudo, inicialmente ocorreu um estudo bibliográfico em sites, livros, artigos e revistas que tratam sobre os assuntos que ele abrange para que fosse possível adquirir mais conhecimentos sobre eles, dando maior suporte teórico para nossas ações. Na sequência foi realizada uma observação exploratória para saber como as crianças do $4^{\circ}$ ano do Ensino Fundamental, da Escola Estadual de Educação Básica Laura Klaudat, localizada em Tunas/RS, veem a fotografia em diversos locais. Os alunos foram instigados a olhar novamente para imagens fotográficas que veem todos os dias e refletir sobre elas, tendo um olhar observador, crítico e curioso sobre o que elas representam, fazendo com que investigassem e fossem investigados ao mesmo tempo. Para isso, começamos com uma observação em uma caminhada pela cidade, observando as imagens fotográficas que ficam presentes no entorno da escola, principalmente nas placas e propagandas do comércio local. 
Depois, conversamos sobre essas imagens e seus usos, instigando os alunos a terem mais curiosidade sobre o assunto. A partir daí, conhecemos um pouco sobre a história da fotografia e observamos as obras da fotógrafa Andréa Brächer que serviram de inspiração para que posteriormente eles pudessem criar suas próprias fotografias. Foi utilizado também como instrumento de pesquisa a coleta de dados e a observação do ambiente onde foram realizadas as interações, bem como anotações a partir de cada encontro e atividade.

\section{A fotografia}

A primeira fotografia durável da história data de 1826, foi de autoria de Joseph Nicéphore Niépce, que junto à Louis Jacques Mandé Daguerre foi um dos precursores das imagens fotográficas. Muitos foram os experimentos e tentativas até chegar ao que pode ser chamado de fotografia. Mesmo assim, um dos primeiros inventos foi o Daguerreótipo, uma espécie de caixa de madeira capaz de gravar imagens permanentemente, mas que tinha um grande problema: seu peso para ser transportado. Depois, veio o Calótipo criado pelo cientista inglês William Henry Fox Talbot (1800-1877) o qual havia conseguido aperfeiçoar o processo de captação de imagens. E assim, aos poucos outros interessados pela fotografia começaram a se dedicar mais em fazer tentativas que poderiam contribuir com a descoberta. Para Chiarelli:

\footnotetext{
Assim que foi oficialmente "inventada" em 1839, na França, praticamente já se instituiu o debate sobre o seu caráter artístico. Numa sociedade como a francesa que, desde pelo menos o período revolucionário iniciado com a Revolução de 1789, mostrava índices de interesse crescente por uma produção visual mais fiel ao entorno, a fotografia só viria a ampliar este interesse. Para muitos franceses, devendo ser a arte uma espécie de duplo do real, não existiria arte mais perfeita do que aquela produzida pela fotografia. (CHIARELLI, 2011, p. 5)
}

Nesse sentido, ela conseguia como ninguém ser o mais realista possível. Por mais que os pintores da época fizessem retratos bastante próximos do real, nem sempre conseguiam mediar a luz exata e as noções de proximidade, então a fotografia era quase milagrosa, conseguindo captar detalhes que dificilmente poderiam ser percebidos. Segundo Eugênia Dantas (2000), talvez tenha sido a percepção do real, da cópia perfeita que fez com que o homem se interessasse cada vez mais em tentar representar a imagem fotográfica com fidelidade, dando a ela a responsabilidade de ser prova da verdade, colocando em prática o ver para crer.

Durante o século XIX, a fotografia começou a se popularizar, mas apenas profissionais conseguiam comprar um aparelho. As pessoas que eram fotografadas precisavam ficar imóveis por um tempo, o que era desconfortável. Além disso, o custo das fotografias era bastante elevado, por isso só faziam registros de momentos considerados muito importantes, como solenidades públicas, casamentos e aniversários.

Eternizar momentos começou a se tornar cada vez mais importante, e fazer registros fotográficos virou algo cada vez mais desejado pelas pessoas de diversas classes sociais. Assim, conforme Chiarelli (2005, p. 5) em pouco tempo essa nova tecnologia começou a ocupar espaços que antes eram preenchidos pela imagem xilográfica e pela gravura em metal. 
Ainda, para completar, além de seu destaque no campo artístico e no cotidiano ela também ganhou destaque como fonte histórica de conhecimento, pois proporcionou que as pessoas pudessem conhecer novas realidades através do mundo das imagens, podendo ter acesso as mesmas de forma completa para que conseguissem tirar suas próprias conclusões, não mais dependendo apenas de cartas e registros escritos.

Ao longo do tempo a fotografia também passou a ser utilizada para a produção ficcional, e é no espaço entre o real e o ficcional que a fotógrafa Andréa Brächer desenvolve seu trabalho artístico. Por meio das imagens fotográficas podemos descobrir muitas informações, conhecer realidades, ver através de ângulos nunca percebidos anteriormente. Segundo Dantas (2000, p. 10) “(...) a história congelada na fotografia pode ser novamente apreciada e contada, para outrem, estimulando canais imagéticos, emocionais, afetivos irredutíveis a explicações classificatórias". É sobre a riqueza de imagens fotográficas congeladas e do debate sobre a própria história da fotografia que se trata o trabalho de Brächer.

\section{Andréa Brächer e "A vinda das fadas"}

Andréa Brächer nasceu em Porto Alegre/RS em 1969. Formada em publicidade e propaganda pela UFRGS, Mestre em História, Teoria e Crítica de Arte, Doutora em Poéticas Visuais, vem pesquisando processos fotográficos históricos desde 2003. Docente e artista, ensina e pesquisa fotografia, especialmente as técnicas de impressão do século XIX, experimentações químicas e os cruzamentos destas com as tecnologias digitais. Atualmente é Professora Adjunta do Departamento de Artes Visuais do Instituto de Artes/UFRGS, conforme consta em seu site. ${ }^{\text {ii }}$

Brächer trabalhou em locais diversos, cursava Publicidade e fazia disciplinas de Artes Visuais ao mesmo tempo. Quando cursou a disciplina de fotografia descobriu que gostava muito desta prática e começou a tirar muitas fotos:

Além de ser um meio que pode ser útil nas áreas da Comunicação, a fotografia é muito
importante na vida de todos. Desde a descoberta, ela passou a ser algo que nos ajuda
a reconstruir ou recuperar a nossa memória, ou recontar a nossa história. Embora a
gente possa trocar a maneira de visualizar as imagens, se fossem em chapas antigas,
de prata, vidro, papel ou até mesmo no celular, ainda continuamos carregando as fotos
dos entes queridos conosco (BRÄCHER, 2007, n.p.).

Toda esta riqueza que a fotografia nos apresenta fica ainda mais nítida através das obras de Brächer que conseguiu conectar seu trabalho a experiência de ser mãe, momento a partir do qual mudou seu foco de pesquisa passando a penetrar o universo infantil. Seus filhos inspiraram seu projeto de doutorado no qual tentava recuperar um pouco da criança que foi através da convivência com eles.

Em 2006, a artista iniciou uma série intitulada “A vinda das fadas". Sobre ela, relata:

Esse nome vem da história de duas crianças inglesas que fotografaram fadas no início do século XX. Elas tomaram uma câmera fotográfica e foram ao jardim, ali elas encontraram duendes e fadas, fotografaram e durante a vida inteira delas, elas mantiveram a história de que realmente elas encontraram com essas fadas e com esses duendes e que arquivos de filmes e as reproduções eram verdadeiras. Ao fim da vida uma delas já com 80 e muitos anos contou a verdade de que elas desenharam as fadas, colocaram com pinos de chapéus as fadas, os desenhos das fadas no jardim e se fotografaram, uma e outra. Então na verdade foi uma grande farsa, uma grande 
brincadeira, mas que muitas pessoas acreditaram ser verdade por ser pelo meio da fotografia, algo que revelava esse mundo sobrenatural e a fotografia sendo uma prova, um documento da realidade, se acreditava isso (BRÄCHER, 2019, n.p.).

Uma história que fez mexer como imaginário de muitas pessoas, que por tempos foi considerada verdade já que não havia vestígios e as investigações técnicas não achavam nada que provasse que elas fossem falsas. Dessa forma a artista criou um universo de ficção rememorando processos experimentais de quando surgiu a fotografia e unindo-os a contos de fadas.

Para Niura Ribeiro (2019), que estudou o trabalho da artista, é instigante pensar a fotografia vista como uma verdade do real que ao mesmo tempo pode registrar o mundo imaginário das fadas, um paradoxo que mostra a capacidade da fotografia de promover falsas verdades, o que acontece há tantos anos e ainda hoje continua acontecendo, agora com recursos digitais que facilitam esse processo. Além da série que inspira essa pesquisa, essa mesma história inspirou uma outra mais recente, "Ficções de um jardim: fotografia e literatura" (2019).

\title{
Projeto a visita das fadas
}

\begin{abstract}
Cada vez mais é verdadeira a ideia de somente se apertar um botão. O ser humano confronta-se com a ilusão de um mundo tecnológico que lhe causa a sensação de que pode dominar tudo e todos mediante as configurações de ferramentas, cada vez mais sofisticadas e complexas, programadas, por ironia, por ele mesmo, e, que, naturalmente, lhe impõe tal programação. Por isso, as hibridações próprias das imagens contemporâneas interessam. (BRÄCHER; et al, 2018, p.2)
\end{abstract}

O ser humano é racional, capaz de criar coisas incríveis. Assim foi com a fotografia e com muitas outras coisas que existem.

Produzir imagens fotográficas pode parecer rotineiro em nossas vidas, mas quando conhecemos a história da fotografia passamos a observá-las de outra maneira, e podemos começar a querer saber mais sobre o assunto. Com esse intuito o projeto "A visita das fadas", inspirado na fotógrafa Andréa Brächer e sua obra "A vinda das fadas", foi desenvolvido. A seguir, é apresentada sua estrutura em nove encontros semanais compreendendo tanto a apresentação da atividade quando o relato da experiência de sua execução junto aos estudantes.

O primeiro encontro se organizou a partir de uma saída de campo pela cidade para observar diferentes tipos de fotografias a partir da qual os alunos produziram registros escritos do que viram, comentando sobre cores, tamanhos, detalhes, local onde estavam etc. As crianças andaram pela rua observando as imagens. Como moramos em uma cidade do interior, a maioria das fotografias observadas foram de cunho comercial.

Uma roda de conversa para reflexão sobre os usos das imagens fotográficas vistas pela turma na saída e em casa ocorreu no segundo encontro. Na sala de vídeo da escola as fotografias das imagens encontradas na cidade foram projetadas e olhamos uma de cada vez observando todos os detalhes. Observamos, também, as imagens trazidas de casa e os alunos foram questionados sobre para que cada uma dessas imagens era usada. Conversamos sobre as imagens publicitárias e se o que elas mostram realmente é verdade, como a foto da moça na 
farmácia com o cabelo impecável e um frasco de xampu: será que só usando aquele produto o cabelo realmente ficaria assim?

No terceiro encontro assistimos o documentário Captured Light, da série Maravilhas Modernas, do canal History Channel sobre a história da fotografia. Apesar de um pouco teórico para as crianças, elas conseguiram captar muitas informações e perceber o quão grandioso foi este invento, o passo a passo de sua criação, as pequenas descobertas que aos poucos nos levaram a realidade que temos nos dias de hoje. O que mais chamou a atenção da turma de uma forma geral foi o tempo que as pessoas precisavam ficar paradas, com o pescoço escorado em suportes para se manter no lugar até a fotografia ficar pronta e a tradição de fotografar adultos e crianças mortas. Esse segundo ponto com certeza foi o que os deixou mais inquietos, pois eles tiveram dificuldades para compreender o porquê deste costume, o qual pareceu extremamente inoportuno e assustador.

No quarto encontro os estudantes realizaram a leitura de um pequeno texto sobre o fotógrafo Eadweard Muybridge e observaram imagens feitas por ele. As crianças acharam muito interessante o experimento feito para mostrar como as pernas do cavalo se moviam no trote através de fotografias e ficaram admiradas em saber que um vídeo são várias imagens que juntas nos dão a sensação de movimento. Alguns inclusive começaram a desenhar e tentar copiar os desenhos dos cavalos do experimento de Muybridge.

No quinto encontro, "A visita das Fadas", os alunos foram recepcionados numa sala de aula decorada, com fadinhas e algumas imagens das obras da Andréa Brächer impressas, além disso havia luzes decorativas e um fundo musical de natureza que foram organizados para que pudessem se aventurar no mundo do faz de contas. Nesse ambiente especial, participaram de uma hora do conto para assim conhecer a história que inspirou a artista.

A curiosidade pelo que estava por vir quando espiaram para dentro da sala tomou conta dos alunos, e seus olhos brilhavam de alegria e interesse. Prestaram atenção como nunca em uma história e a partir deste dia passaram a chamar a artista de Andréa, como se a conhecessem pessoalmente, com intimidade. Ela passou a constar inclusive em atividades de outras disciplinas, como por exemplo em Língua Portuguesa, onde ao pedir que escrevessem um substantivo próprio vinha a resposta: Andréa.

No nosso sexto encontro fomos até a sala de vídeo da escola e assistimos alguns vídeos sobre os fotógrafos já apresentados, percebendo as fotografias de Eadweard Muybridge usadas para provar a realidade e as fotografias de Andréa Brächer que distorcem a realidade a partir da ficção. Conversamos sobre o assunto e os alunos levantaram pontos importantes, comentando sobre a edição de imagens e o quanto isso pode ajudar ou até mesmo prejudicar alguém. Outro fator que os deixou impressionados foi ao assistir o vídeo da Andréa sobre a obra "A vinda das fadas" perceber o quanto é trabalhoso montar uma exposição e como elas acontecem. E assim foram criando diversas possibilidades em torno do que haviam visto.

O sétimo encontro foi o dia de ser artista e produzir as próprias fotografias. Utilizando os personagens e fadas feitos anteriormente em casa, fomos até a praça da cidade fazer registros fotográficos. Cada aluno foi montando seu próprio cenário, colocando os personagens (fadas, anjos, frutas, Garfield, ratinhos, Minecraft, entre outros) em diversos lugares, prendendo-os com fios de nylon, espetando nos espinhos das plantas, escorando onde conseguiam. Os que tinham seus próprios smartphones foram fazendo os registros fotográficos e os que não tinham 
usaram o da professora. Fizeram fotos coloridas, pretas e brancas e algumas com filtros variados. Ao voltarmos para escola fomos até a sala de vídeo olhar como haviam ficado esses registros e escolher aqueles que considerávamos mais interessantes.

Em nosso oitavo encontro conversamos com Andréa Brächer para apresentar nosso trabalho a ela e para conhecê-la virtualmente por meio de uma videochamada. Anteriormente havíamos enviado um e-mail para artista contando um pouco sobre o nosso projeto e fazendo o pedido de que ela conversasse conosco. Combinamos o dia e horário e ficamos aguardando ansiosos.

Ela contou sobre o seu trabalho, sobre como surgiu o interesse pela fotografia, relatou experiências que realizou e os processos da obra "A vinda das fadas" bem como alguns aspectos de sua vida pessoal. Aproveitou ainda para nos mostrar um Talbótipo, uma caixa de madeira de tamanho médio que se constituía por uma câmara escura, e explicar como ele funcionava. Essa foi a parte em que os olhinhos das crianças ficaram sem piscar, interessados e cheios de curiosidade. Para encerrar, ainda fizemos algumas perguntas que haviam sido previamente organizadas e selecionadas pela turma.

No nono e último encontro para finalizar nosso projeto com chave de ouro, realizamos uma exposição das fotografias feitas pelos alunos e convidamos as outras turmas de séries iniciais da escola para virem a nossa sala assistir. Nesse mesmo dia também iria acontecer a entrega de boletins dos alunos e os pais foram convidados para prestigiarem a exposição. Dessa forma preparamos e organizamos a sala novamente como um jardim encantado.

Os alunos foram previamente organizados pela professora para que todos pudessem contribuir na hora da apresentação e contaram aos convidados como foi o desenvolvimento do nosso projeto. Foi um momento de consolidação de tudo aquilo que havíamos estudado há tantas semanas. As crianças souberam apresentar com autenticidade o assunto. Eles dominaram os conhecimentos adquiridos através do projeto por meio de atividades simples, mas que se revelaram interessantes e significativas.

A exposição virou assunto na escola, todos queriam vê-la, e a atividade que era para ser só para os colegas das turmas até $5^{\circ}$ ano do Ensino Fundamental foi visitada pelos $6^{\circ}, 7^{\circ}, 8^{\circ} \mathrm{e}$ $9^{\circ}$ anos também, os quais ficaram impressionados: como que o $4^{\circ}$ ano já sabia tantas coisas que eles ainda não conheciam? A resposta a tal indagação reside na aprendizagem significativa integrando teoria e prática, mediada pela curiosidade, pela troca e também pelo interesse em aprender com os outros, não importando se são mais novos ou mais velhos, percebendo que sempre temos mais conhecimentos a adquirir. Assim é possível afirmar que o projeto foi uma experiência que acabou por atingir e integrar estudantes de toda a escola e não apenas a turma de quarto ano para a qual havia sido originalmente pensado e planejado, e até mesmo os pais, que também visitaram a exposição.

\section{Considerações finais}

Emoção, alegria, aprendizagem e conhecimento são as palavras que descrevem esse momento de tecer considerações sobre o projeto. Estudar a história da fotografia com certeza é um grande desafio, pois existem muitas informações, mas elas não se encontram em um só lugar. A fotografia foi tanto inventada como descoberta ao mesmo tempo por muitas pessoas em diversos lugares do mundo. Isso faz com que ao estudá-la seja necessário reunir os mais 
variados pedacinhos da história e reconstruí-la da nossa maneira, para melhor entendê-la e ensiná-la. Montar esses pedacinhos de história e pequenas descobertas e ainda tornar toda essa riqueza de conteúdos em algo simples para que crianças entre 10 e 11 anos entendam, se torna um desafio ainda maior.

Todavia, fotografar se tornou parte da nossa rotina e fazemos isso tão automaticamente que nem paramos para nos perguntar de onde vem as coisas, como elas são feitas, se sempre foi assim. Nesse sentido, o projeto "A visita das fadas" veio com o intuito de aguçar crianças a investigarem sobre a fotografia, a conhecer sobre o assunto e entender como ela chegou em nossas vidas. A experiência de Eadweard Muybridge com os cavalos e o trabalho da artista e professora Andréa Brächer com sua obra "A vinda das fadas" foram cruciais para prender a atenção das crianças e fazer com que eles entendessem melhor o poder da fotografia, a mágica por de trás de uma imagem fotográfica, o como isso é possível atualmente e todas as etapas que tiveram que ser realizadas até chegar no que temos hoje.

Através do projeto, os pequenos alunos do $4^{\circ}$ ano descobriram as origens da fotografia, seus usos e, através do contato com o trabalho de Andréa Brächer, puderam conceber também a fotografia como arte e produzirem suas próprias imagens, pequenos artistas em suas primeiras experimentações. Além disso, o contato com a artista foi muito importante. Diante de minha afirmação de que tentaria entrar em contato com ela para a realização do encontro, os estudantes ficaram entusiasmados e com expectativas, ficando muito felizes com a confirmação da atividade e com a realização da conversa. Nesse sentido, o projeto também lhes mostrou que podemos vencer distâncias, e que o mundo do conhecimento não tem limites.

Além disso, o projeto que foi inicialmente pensado para a turma do $4^{\circ}$ ano, ao ser apresentado para as demais turmas de séries iniciais, virou o assunto da escola e os outros alunos, das séries finais do Ensino Fundamental também quiseram ver. Os pais dos alunos que foram retirar seus boletins no dia em que estava acontecendo a exposição também foram prestigiar os trabalhos, o que era um projeto da turma, acabou tomando proporções muito maiores do que pretendíamos inicialmente, passando a ser um projeto que envolveu toda a comunidade escolar de uma forma muito significativa, atingindo fronteiras muito além das quais estavam propostas no objetivo geral inicial do projeto que era apenas perceber a fotografia e seus usos.

Para além da realização bem-sucedida do projeto até aqui, também é importante destacar que ele já apresentou como resultado a participação da turma na Feira Municipal do Conhecimento, representando a nossa escola e conquistando o $1^{\circ}$ lugar na categoria Anos Iniciais do Ensino Fundamental. Na sua continuidade, pretende-se desenvolver estudos e atividades com foco na análise de imagens, levando em conta os aprendizados observados a partir da presente investigação.

\section{Referências}

ABREU, ELANE. Imagens banais e revelatórias: dilemas e desejos das fotografias como resto $C \& S$ - São Bernardo do Campo, v. 35, n. 1, p. 251-275, jul./dez. 2013. Disponível em: http://dx.doi.org/10.15603/2175-7755/cs.v35n1p251-275. Acesso em: 05 ago. 2021. 
BRÄCHER, Andréa. Andréa Brächer, 2019. Artista visual. Disponível em: https://www.andreabracher.com.br/. Acesso em: 25 ago. 2021.

BRÄCHER, Andréa. Andréa Brächer. IHU Online. Edição 231, 13 de agosto de 2007. Disponível em: http://www.ihuonline.unisinos.br/artigo/1221-ihu-reporter-36. Acesso em: 1 out. 2021.

BRÄCHER, Andréa; et al. Herdeiros de Herschel: práticas alternativas em fotografia contemporânea. In Anais: $27^{\circ}$ Encontro da Associação Nacional dos Pesquisadores em Artes Plásticas, São Paulo, 24 a 28 de setembro de 2018. Anais do $27^{\circ}$ Encontro da Anpap. São Paulo: Universidade Estadual Paulista (UNESP), Instituto de Artes, 2018. p.2749-2765. Disponível em: http://anpap.org.br/anais/2018/content/PDF/27encontro BR\%C3\%84CHER_Andr\%C3

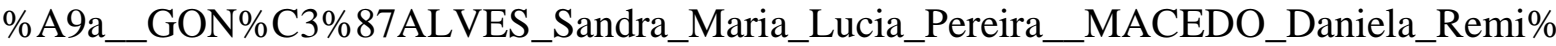
C3\%A30_MOREIRA_Jussara_GON\%C3\%87ALVES_Myra_Adam_de_Oliveira.pdf Acesso em: 25 set. 2021

CHIARELLI, Tadeu. História da Arte/história da fotografia no Brasil - século XIX: algumas considerações. ARS (São Paulo), vol. 3 n.6, 2005, p. 1- 10. Disponível em: https://www.scielo.br/j/ars/a/KwBpXZhjbZYQwcTqC6z4xWG/?format=html. Acesso em 03 jun. 2021.

DANTAS, Eugênia Maria. Educação-fotografia: impressões e sentidos. IN: Anais da 23a Associação Nacional de Pesquisa em pós-graduação (ANPEd), Caxambu - MG, 24 a 28 setembro, 2000.

Disponível em: https://www.anped.org.br/biblioteca/item/educacao-fotografia-impressoes-esentidos. Acesso em 03 jun. 2021

LAKATOS, Eva Maria; MARCONI, Marina de Andrade. Técnicas de pesquisa: planejamento e execução de pesquisas, amostragens e técnicas de pesquisa, elaboração, análise e interpretação de dados. 6. ed. São Paulo: ATLAS, 2006.

RIBEIRO, Niura Aparecida Legramante. Ficções de um jardim: fotografia e literatura Exposição de Andréa Brächer. In Anais: $28^{\circ}$ Enconto Nacional da Associação Nacional de Pesquisadores em Artes Plásticas, Goiás, 16 a 20 de setembro, 2019. Goiânia: Universidade Federal de Goiás, 2019. p. 302-311. Disponível em: http://anpap.org.br/anais/2019/PDF/ARTIGO/28encontro__RIBEIRO_Niura_Aparecida Legramante 302-311.pdf Acesso em: 26 set. 2021

VIEIRA. José Guilherme Silva. Metodologia de pesquisa científica na prática. Curitiba: FAEL, 2011.

\footnotetext{
' A presente pesquisa foi desenvolvida no curso de Especialização em Artes do Centro de Artes da UFPEL, com orientação do professor Ricardo Henrique Ayres Alves.

ii Disponível em: https://www.andreabracher.com.br/. Acesso em: 25 ago. 2021.
} 